\title{
HOPE Mask Designed to Subdue Self-Adjustable Porosity and Reduced Exposure to Micro and Nano Particles
}

\author{
Saloni Jethwa \\ Department of Biomedical Engineering, \\ Lalbhai Dalpatbhai College of Engineering, \\ Ahmedabad, India
}

\author{
Anudruti Singha \\ Biomedical and Sensors \\ (School of Electronics Engineering) \\ Vellore Institute of Technology
}

\begin{abstract}
Health is a fundamental piece of everybody's life, except contamination is slowly expanding. That makes some ongoing medical issues, for example, Asthma, Lung Disease, Cardiovascular issues, and cause disease in the eye, nose, and throat. So for controlling this adverse impact, present a HOPE Mask. At whatever point particles and pressurized canned products are reaching with fiber around, then particles are effectively retained, and fresh air is delivered to individuals. Polyvinylpyrrolidone (PVP) and Ethanol are principally utilized to make filter material and nanofibers produced by utilizing the Electrospinning technique. The nanofiber cover material is portrayed by Observation, Air permeability, and Porosity test. The outcome shows that PVP is suitable for expelling poisons particles from the air and giving an outside air to the individuals.
\end{abstract}

Keywords- Polymer nanofibers; electrospinning process; generating fibers; Hand-held electrospinning setup; valve; Filter

\section{INTRODUCTION}

Contamination is expanding in both urban and country zone. After research, Delhi is an exceptionally polluted city among different urban areas in India. The focus level of "Respiratory Suspended Particulate Matter" found noticeable all around is most noteworthy in Delhi. [1], [2] Pollution is separated into two class's indoor and open-air. Indoor contamination is producing by conventional biomass cooking, space warming, and lamp oil, while outside contamination is created by vehicles, businesses, and consuming fireworks. [1], [3] Due to indoor and outside contamination, there are different toxics gases and particles created, for example, carbon dioxide, sulfur dioxide, nitrogen, PM2.5, and PM10. The transportation produces half of the nitrogen, and that contamination makes an antagonistic impact on almost every organ's functionality. Air contamination is strongly ascending in cardiovascular illness, respiratory malady, lung harm, and even passing. [4], [1], [3] The size of the particulate issue is so littler than the hair, so it can, without much of a stretch, enter in tissue since it can infiltrate human lungs and bronchi. Consequently, the long-haul persistence of PM2.5 and PM10 increases the mortality and dismalness rate. [1], [3], [4], [5] So, in the current scenario, the mask is for everybody. A contamination mask is worn over the nose and mouth. It separates hurtful dirtied Nano particles, such as PM2.5 (breadth going from 1 to $2.5 \mu \mathrm{m}$ ) and PM10 (breadth going from 2.5 to $10 \mu \mathrm{m}$ ) when the outside air is pumped to the individuals. Breathing in pure air is useful to build the lung limit and makes breathing simpler, and it likewise enlarges respiratory muscles and expands the oxygen consumption

\section{MATERIALS AND CHEMICALS}

Polyvinylpyrrolidone is one sort of engineered polymer making out of direct 1-vinyl-2 pyrrolidone gatherings. [6], [8] PVP has a carbon chain, including an amide bunch along the edge and opposite side, having poly-n-vinlamide. [10], [6], [8] Commercially available PVP is separated into four thickness grades as indicated by its press $\mathrm{K}$ esteem (Fikentscher $\mathrm{K}$ esteem): K-15, K-30, K-60, K-90, [12] with the average sub-atomic weight being 10,000, 40000,160000, and 360000, individually. As indicated by the sub-atomic weight properties of PVP is changed, and it has decent biocompatibility and capacity in K-90 contrast with K-15. [10], [8] In HOPE Mask, $\mathrm{K}-30$ evaluation of PVP is utilized because the sub-atomic load of that evaluation is profoundly reasonable for making fibers. PVP is accessible in powder structure, so it requires some investment to blend in with liquid ethanol. PVP is accessible as it is ease and lightweight, so it can be used without much of a stretch moderate for people. When PVP blends in with Ethanol, the quality of that cover is profoundly promising considering carbon shock, in concoction can separate more PM2.5 particles.

Ethanol is one of the most significant natural synthetic compounds [13] utilized in mechanical and purchaser items. In HOPE Mask 99\% pure Ethanol is used. Ethanol's properties are combustible, dry fluid with a breaking point of $78.5^{\circ} \mathrm{C}$ [14]. An arrangement of 70-85\% of Ethanol, used as a disinfectant; it slaughters creatures by denaturing their proteins and dissolving their lipids: it is powerful against most microscopic organisms, viruses and growths numerous infections, [14], [13] however are incapable against bacterial spores. Ethanol's disinfectant property is the explanation that mixed drinks can be put away for quite a while.

Nonwovens are inventive, front line, assembled surfaces created utilizing fibers. They are used to a wide extent of the customer and current things either, in the mix with various materials or alone. Non-woven may be a limited life, single-use surface, or a totally solid surface. Nonwoven surfaces give express limits, such as retentiveness, liquid repellency, adaptability, stretch, non-abrasiveness, quality, fire retardancy, wash limit, cushioning, isolating, and bacterial checks, and sterility. Non-woven material, utilized as a subtractor and it covers the channel. Some portion of the mask 
is sandwiched between non-woven materials. Non-woven materials are accessible easily and the GSM (Grade Me) of the materials chooses Non-woven materials. Higher the GSM higher it can make a thick cover and strength of the mask. In this Mask, 1800 GSM texture of Non-Woven is utilized.

\section{PROCEDURE}

\section{A. Procedure for Electrospinning}

Polyvinylpyrolidone (PVP) and Ethanol are utilized as fiber materials, while Non-woven is utilized as a subtractor. Various kinds of PVP are accessible, yet the sub-atomic load of K-30 is very reasonable for making a fiber given their diploes development. The PVP powder is blended in with Ethanol, and the centralization of both the synthetic is $14 \%$. Though $7 \%$ of PVP is utilized, and $2 \mathrm{ml}$ of Ethanol is utilized. The electrospinning technique is utilized for making a fiber. The plan of Electrospinning was set up by syringe and roller. PVP arrangement was set up at a convergence of 14\% dissolving in Ethanol with incredible blending. The readied arrangement is kept for more than 3 hours at 300RPM for the blending process for evacuating an air bubbles structure the arrangement as shown in figure. 1 .

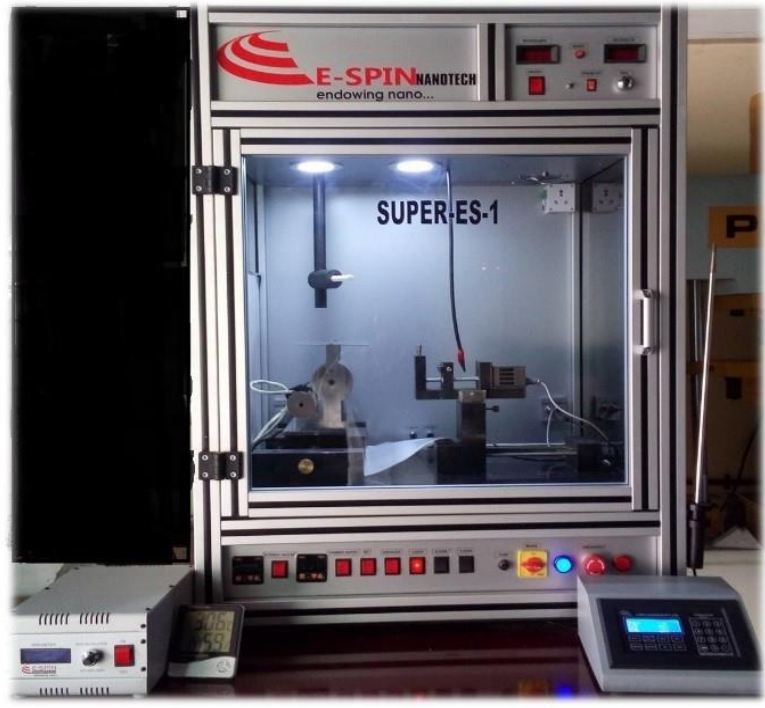

Figure (1)- Electrospinning machine

For Electrospinning, the 14\% PVP arrangement is filled into a syringe with a metal needle associated with high force gracefully. The syringe is situated away from about $15 \mathrm{~cm}$ between the metal tip and the gatherer. At the authority side, non-woven material is set on the roller. The width and length of the roller are $26 \mathrm{~cm}$ and $15 \mathrm{~cm}$ separately. When the current is applied at a time, electrostatic aversion happens that extended the bead and that beads are changed over into strands gathered at a roller side, as shown in figure. 2 .

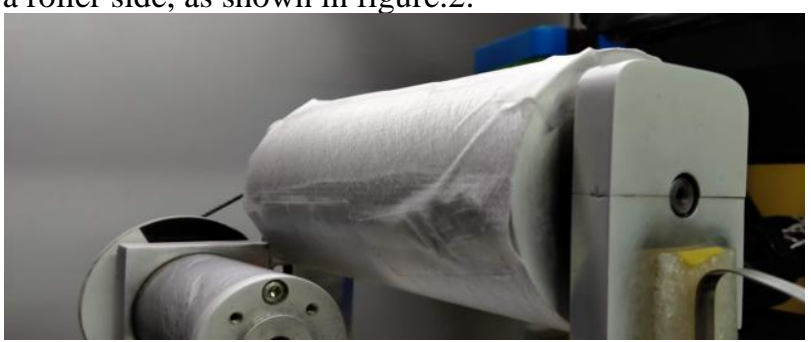

Figure (2)- The readiled arrangment for collecting the fiber

\section{B. Procedure for Air Permeability}

To test the air penetrability of the filter may be executed in ASTM D737 Machine. Within sight of weight evaluation on the two aspects of the filter, the extent of air moving thru the filter material in step with unit and region in line with unit time beneath the predefined tension distinction between the one of a kind of the filter. The example of a filter is constant to the look at zone via the handle. A concrete aspirator pump begins to draw air through an interchangeable check head at a circular commencing by squeezing the test head to begin the test. The preset look at strain is consequently begun and stored up for more than one moment, the air penetrability of the tried instance is shown in a preset unit of estimation. Press the test head once more for one second, the instance is discharged, and the suction equipment siphon is shut.

\section{Procedure for Porosity Test}

ASTM D6767 Test Method for Pore Size Characteristics of Filters by Capillary Flow Test is a test technique where a wetting liquid is utilized to soak the filter test's pores, trailed by a non-responding gas that dislodges the juice from the filter pores. A filter test is cut and put into the test gadget's office to play out the test. The porometer powers air through the dry example, taking estimations at various valve position increases (cc/min or $1 / \mathrm{min}$ ) and different weights (psi, $\mathrm{kPa}$ ). At the point when the most extreme foreordained value or stream rate is reached, the testing gadget resets, preparing for the second period of the test. Next, the filter test is soaked with a wetting liquid with a known surface strain and exposed to another arrangement of weight and stream rate estimations. The crude information from these estimations is gone through a progression of counts to decide the base, most extreme and mean pore size, filter stream rate, and pore size dispersion. The Table. I give an entire overview of the process flow and system specification

\begin{tabular}{|l|l|l|l|l|l|}
\hline Polymer & Solvent & $\begin{array}{l}\text { Flow } \\
\text { Rate }\end{array}$ & Distance & Voltage & Time \\
\hline $\begin{array}{l}\text { PolyvinylP } \\
\text { yrrolidone } \\
(7 \%\end{array}$ & $\begin{array}{l}\text { Ethanol } \\
(2 \mathrm{ml} \\
\text { solution })\end{array}$ & $1 \mathrm{ml} / \mathrm{hr}$ & $15 \mathrm{~cm}$ & $15 \mathrm{Kv}$ & 20 to \\
$\begin{array}{l}\text { concentrati } \\
\text { on of } \\
\text { powder) }\end{array}$ & & & & $\begin{array}{l}30 \\
\mathrm{~min}\end{array}$ \\
\hline
\end{tabular}

Table (I)- Entire Process Flow and system specification IV. DESIGN

The below shown diagram in figure. 3 shows the assembly and the design specification of the mask.

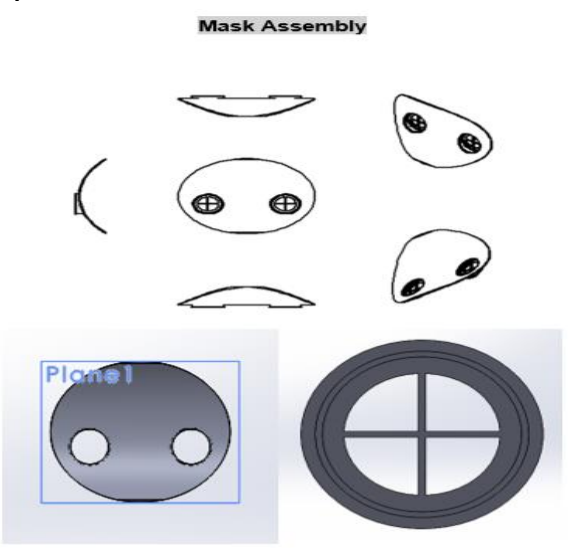

Figure (3)- Assembly and design 


\section{RESULT AND DISCUSSION}

The filter's aftereffect fundamentally relies upon Fiber diameter, porosity (the proportion of open space to filaments), and channel thickness. All assume a job in how well fibers gather particles. In every single sinewy fiber, three "mechanical" assortment instruments work to catch particles: inertial impaction, capture, and dispersion. Inertial impaction and interference are the systems answerable for gathering bigger particles, while dispersion is the instrument liable for gathering littler particles. In some sinewy filter built from charged fibers, a different instrument of electrostatic attraction also operates. This system helps in the assortment of both more significant and littler molecule sizes.

\section{A. Morphological Observations}

After the Electrospinning strategy, the thickness of fiber is distinctive in 20 and 30 minutes. In this strategy, point type Electrospinning is utilized, so in light of this thickness is more at focal part contrast with the side of the Non-woven texture. The thickness of fiber is more in 30 minutes. $(20 \mathrm{~min}<30$ $\mathrm{min})$. Illustrated in the figure. 4

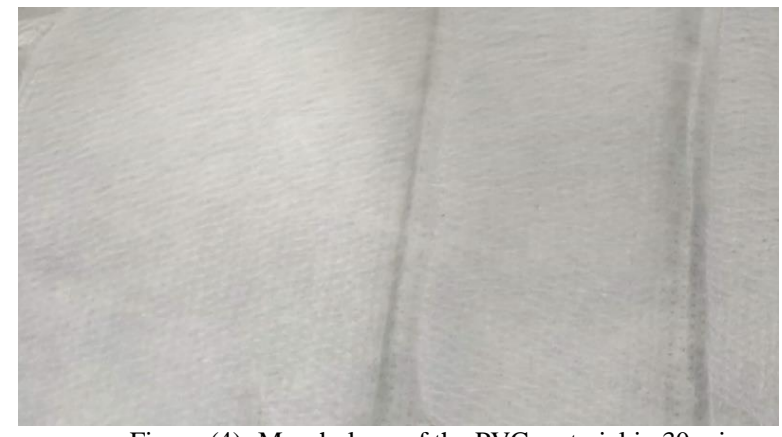

Figure (4)- Morphology of the PVC material in $30 \mathrm{~min}$

More thickness absorbed fewer pollutant particles in PVP, so 20 minutes fiber is more appropriate for removing PM2.5. Illustrated in the figure. 5

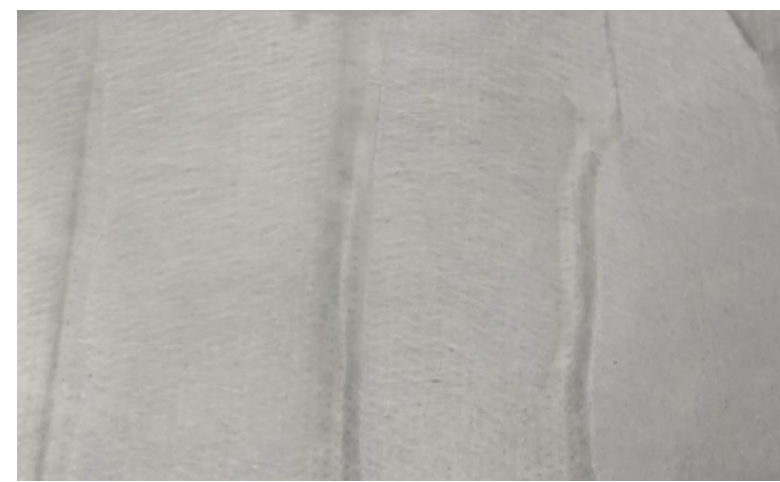

Figure (5)- Morphology of the PVC material in 20 min

\section{B. Air Permeabilty test Results (ASTM D 737)}

Two results are calculated for two filters: one is of 20-minute fiber, and another is 30-minute threads. The filter is placed in the ASTM D 737 machine and applied 125 Pascal at the filter's fiber side. After 15 minutes result is shown in that 20-min fiber is 34 Pascal while 30 minute of threads is 35 Pascal. Air Permeability in 30 minutes is more but in the mask, if there is less permeability means higher the removal efficiency of pollutant particles. It implies that the result shows that thickness is inversely proportional to Air permeability. While in PVP, if the thickness is less extract, more pollutant particles are absorbed. The Table II shows the entire Test Parameters and results of the Air Permeability Test.

Unit- cfm

Table (II)- Test Parameters of Air Permeability

\begin{tabular}{|c|l|c|c|}
\hline \multicolumn{1}{|c|}{ Method } & \multicolumn{1}{|c|}{ Test Method } & 20 min & 30 min \\
\hline Air Permeability & ASTM D 737 & 34 & 35 \\
& $\begin{array}{l}\text { Pressure }: 125 \mathrm{~Pa} \\
\text { Test Area }: 38 \mathrm{~cm} 2 \\
\text { Unit }: \mathrm{cfm}\end{array}$ & & \\
& & & \\
\hline
\end{tabular}

\section{Porosity test Results (ASTM D 6767)}

Poison particles are small; they must require high porosity. While in 20 minutes, fibers with the most significant pore size are 17 micron though the least strands' porosity is 12 . In 30 minutes, fibers have the most extreme pore size 18 micron, and the least is 13 . So it shows that porosity is excellent in a short time filter because less pore size can consume more toxin particles-the Table. III shows the entire Test Parameters and results of the Porosity Test.

Unit- Micron.

\begin{tabular}{|l|l|l|l|}
\hline Test Parameters & $\begin{array}{l}\text { Sample 1 } \\
(\mathbf{2 0} \text { min })\end{array}$ & $\begin{array}{l}\text { Sample 2 } \\
(\mathbf{2 0} \text { min })\end{array}$ & $\begin{array}{l}\text { Sample 1 } \\
(\mathbf{3 0} \text { min })\end{array}$ \\
\hline Max Pore Size & 17.224 & 17.198 & 18.089 \\
\hline Min Pore Size & 12.443 & 12.063 & 13.397 \\
\hline
\end{tabular}

Table (III)- Test Parameters of Porosity Test

\section{CONCLUSION}

The filaments assume a significant job in the channel, which is valuable for catching some impeding particles from the air. The scopes of gatherings are shifts from not many microns to twenty nanometers. By hindering the particulate issues gives higher lung limit and breath natural air. This improves the quality of respiratory muscles and builds oxygen admission. The electrospinning strategy helps produce filaments that are valuable for blocking particulate issues. The air penetrability and porosity test show the consequence of catching air particles. The central point of our mask is to make practical and reuse.

\section{REFERENCES}

[1] G. O. Young, "Synthetic structure of industrial plastics (Book style with paper title and editor)," in Plastics, 2nd ed. vol. 3, J. Peters, Ed. New York: McGraw-Hill, 1964, pp. 15-64.

[2] W.-K. Chen, Linear Networks and Systems (Book style). Belmont, CA: Wadsworth, 1993, pp. 123-135.

[3] H. Poor, An Introduction to Signal Detection and Estimation. New York: Springer-Verlag, 1985, ch. 4.

[4] B. Smith, "An approach to graphs of linear forms (Unpublished work style)," unpublished.

[5] E. H. Miller, "A note on reflector arrays (Periodical style-Accepted for publication)," IEEE Trans. Antennas Propagat., to be published.

[6] J. Wang, "Fundamentals of erbium-doped fiber amplifiers array (Periodical style-Submitted for publication)," IEEE J. Quantum Electron., submitted for publication.

[7] C. J. Kaufman, Rocky Mountain Research Lab., Boulder, CO, private communication, May 1995. 
[8] Y. Yorozu, M. Hirano, K. Oka, and Y. Tagawa, "Electron spectroscopy studies on magneto-optical media and plastic substrate interfaces(Translation Journals style)," IEEE Transl. J. Magn.Jpn., vol. 2, Aug. 1987, pp. 740-741 [Dig. $9^{\text {th }}$ Annu. Conf. Magnetics Japan, 1982, p. 301].

[9] M. Young, The Techincal Writers Handbook. Mill Valley, CA: University Science, 1989

[10] (Basic Book/Monograph Online Sources) J. K. Author. (year, month, day). Title (edition) [Type of medium]. Volume(issue) Available: http://www.(URL)

[11] J. Jones. (1991, May 10). Networks (2nd ed.) [Online]. Available: http://www.atm.com

[12] (Journal Online Sources style) K. Author. (year, month). Title. Journal [Type of medium]. Volume(issue), paging if given. Available: http://www.(URL) 